\title{
Ultraestructura del compartimiento clase II en macrófagos humanos en rosetas macrófago-linfocitarias autólogas
}

\author{
Natalia S. Infante ${ }^{1}$, Ivón T. C. Novak ${ }^{1 *}$
}

\begin{abstract}
Resumen - Introducción: El procesamiento y presentación de antígenos está involucrado en el fenómeno de múltiples sinapsis inmunológicas de la Roseta Macrófago-Linfocitaria humana (RML) entre macrófagos derivados de monocitos y linfocitos T CD4+ de cultivos autólogos leucocitarios totales extraídos de la sangre; aquí los antígenos autólogos de los neutrófilos apoptóticos son presentados por la vía endocítica o vía Clase II. El Compartimiento Clase II (CCMII) ha sido caracterizado en células B y células dendríticas en modelos murinos. Objetivo: estudiar la evolución ultraestructural de la organización espacial CCMIl en macrófagos en el fenómeno de RML humana. Métodos: Se utilizaron muestras de sangre humana sana, anticoagulada con heparina ( $\mathrm{n}=10)$ donadas por Banco de Sangre, UNC, en anonimato. Cultivos leucocitarios autólogos en medio TC199 (SIGMA, St. Louis, MO). Se tomaron muestras de cultivo celular a: 1, 2, 3, 20, 48 y 96 horas. Se aplicó la técnica de RML. Las citopreparaciones se sometieron a técnicas de procesamiento para su estudio ultraestructural con el MET: Zeiss LEO-906E. Resultados: Observamos cuerpos multivesiculares, multilaminares y tubulares en la organización espacial del CCMII a lo largo del tiempo de cultivo. Estructuras tubulares aparecieron a las 48 horas de cultivo. Se concluye que organización espacial del CCMII toma diversos aspectos en coincidencia con la ocurrencia de transformación macrofágica en cultivo y su rol como célula presentadora de antígenos (CPA) en RMLs. Dado el origen autólogo de los antígenos presentados postulamos que el perfil de los macrófagos en RMLs podría corresponder al alternativo o $\mathrm{M}^{2}$.
\end{abstract}

Palabras clave: compartimiento clase Il; procesamiento y presentación de antígenos; roseta macrófago linfocitaria humana; linfocitos; macrófagos

Abstract - Introduction: Processing and presentation of antigens is involved in the phenomenon of multiple immunological synapses of human Macrophage-Lymphocyte Rosette (MLR) between monocyte-derived macrophages and CD4 + T cells of total leukocyte cultures autologous extracted from blood; here autologous apoptotic neutrophil antigens are presented by the endocytic pathway or via Class II. Class II Compartment (MIIC) has been characterized by B cells and dendritic cells in murine models. Objective: To study the ultrastructural evolution in the spatial organization MIIC in macrophages in the phenomenon of human MLR. Methods: healthy human blood samples were used, anticoagulated with heparin $(n=10)$ donated by Blood Bank, UNC, anonymous. Autologous leukocyte cultures in TC199 medium (SIGMA, St. Louis, MO). Cell culture samples were taken at 1, 2, 3, 20, 48 and $96 \mathrm{~h}$. MLR technique was applied. The citopreparations underwent processing techniques for ultrastructural study with MET: Zeiss LEO-906E. Results: We observed multivesicular, multilamellar, and tubular bodies in the spatial organization of MIIC throughout the culture time. Tubular structures appeared at $48 \mathrm{~h}$ of culture. We conclude that spatial organization of MIIC takes various aspects coinciding with the occurrence of macrophage transformation in culture and its role as antigen-presenting cell (APC) in MLRs. Given the autologous antigens presented we postulate that the profile of macrophages in MLRs could correspond to alternative or $\mathrm{M}^{2}$.

Keywords: class II compartment; antigen processing and presentation; human lymphocyte macrophage rosette; lymphocytes; macrophages

Fecha de envío: 01 de Noviembre de 2015 - Fecha de aceptación: 26 de Noviembre de 2015

1) Instituto de Biología Celular, Facultad de Ciencias Médicas, Universidad Nacional de Córdoba. Argentina

*Autor de correspondencia: inovak@cmefcm.uncor.edu 


\section{Introducción}

La iniciación de respuestas inmunes adaptativas comprende el procesamiento y presentación de antígenos a los linfocitos $\mathrm{T}$, quienes requieren de Células Presentadoras de Antígenos (CPAs), para que con sus moléculas del Complejo Mayor de Histocompatibilidad (CMH) expresadas en la superficie celular les presenten los péptidos antigénicos para ser reconocidos por su receptor de célula T (TCR). El procesamiento antigénico involucra la acción de proteasas que cortan a la proteína antigénica en pequeños péptidos, que se asocian con moléculas Clase I y Clase II del CMH sintetizadas por las CPAs que luego se expresan en la superficie celular (Fainboim \& Geffner, 2011; Neefjes et al., 2011; Murphy, 2012). Dichas moléculas del CMH se expresan diferencialmente en los distintos tipos celulares. Los macrófagos, las células dendríticas y los linfocitos $B$, denominados CPAs "profesionales", expresan moléculas Clase Il además de Clase I. Durante el reconocimiento del antígeno según el tipo de célula T, las moléculas co-receptoras CD4 o CD8 se asocian con el TCR y se unen a zonas invariantes de la molécula Clase II o Clase I, respectivamente. Existen varias vías de procesamiento y presentación de antígenos: la vía Clase I o biosintética o endógena, la vía Clase Il o endocítica o exógena, las vías cruzadas, combinación de las anteriores y otra diferente, la vía del CD1 para presentación de antígenos lipídicos (Fainboim \& Geffner, 2011; Neefjes et al., 2011; Murphy, 2012).

Microorganismos extracelulares y materiales propios del organismo tales como células apoptóticas o macromoléculas de la matriz extracelular, entre otros, pueden ser endocitados, procesados y presentados por la vía Clase II (Abbas et al., 2012; Murphy, 2012).

Los macrófagos son las células encargadas del reconocimiento y fagocitosis de células propias que sufren apoptosis naturalmente en el organismo. Los neutrófilos apoptóticos expresan en su membrana la molécula fosfatidilserina la cual es reconocida por los macrófagos para su fagocitosis (Fainboim \& Geffner, 2011). Además, estas células actúan como una bisagra en la inmunidad, ya que no solo tienen como objetivo digerir el patógeno, sino que inducen a que se produzca una respuesta adaptativa para generar efectores y memoria inmunológica (Fainboim \& Geffner, 2011). La molécula Clase II, se sintetiza en el retículo endoplásmico (RE) unida a una cadena invariante (li) que tiene la función de bloquear la hendidura de unión peptídica de la molécula Clase Il dentro del RE, y de dirigir a esta hacia el compartimento endosómico. La cadena invariante sufre sucesivas divisiones, a medida que la molécula Clase II va migrando en la célula. En el endosoma queda un fragmento peptídico corto, el CLIP (Class II-associated Invariant-chain Peptide, péptido de la cadena invariante asociado a Clase II) aún bloqueando el sitio de unión de la molécula Clase II, que más tarde se liberará quedando la hendidura expuesta para unirse a los péptidos antigénicos gracias a la molécula HLA-DM, propia de un compartimiento intracelular especializado denominado CCMII (compartimiento del CMH clase II) o MIIC (MHC class II compartment) en la CPA. Una vez que se carga el péptido el complejo viaja a la superficie celular para ser reconocido por el linfocito Th CD4 (Abbas et al., 2012; Murphy, 2012).

Actualmente el área de contacto entre una célula T y una célula presentadora de antígenos es conocida, como "sinapsis inmunológica" (SI) (Grakoui et al., 1999; Dustin et al., 2001; Lee et al., 2002) y las múltiples interacciones que ocurren conducen a una "señalización" eficiente y específica para la activación de la célula T. Sin embargo, una SI puede ocurrir en diferentes circunstancias, para una variedad de funciones. Se ha propuesto que una de sus funciones claves es generar un micro-ambiente que favorece las interacciones de moléculas co-estimuladoras (Bromley et al., 2001).

En la organización de las proteínas en el área de contacto entre una célula T y una CPA en experimentos in vitro se han descripto dos regiones: una central denominada c-SMAC (central supramolecular activation complex): conteniendo el TCR y moléculas de señalización asociadas y una periférica denominada p-SMAC (peripheral supramolecular activation complex), conteniendo LFA-1 y talina (Lin et al., 2005; Mitxitorena et al., 2015). En cuanto a los organoides celulares, tempranos trabajos han reportado que durante el contacto célula-célula, el TCR y otros co-receptores causan la polarización de la célula $T$, remodelando el citoesqueleto de actina y reposicionando el aparato de Golgi y el centro organizador de microtúbulos entre el núcleo y el área de contacto (Kupfer et al., 1983; Kupfer \& Dennert, 1984).

En el caso de la presentación antigénica vía Clase II, como se mencionó antes, se ha observado a través de microscopía electrónica el compartimiento intracelular especializado CCMII en la CPA con una apariencia multilaminar característica (Abbas et al., 2012; Murphy, 2012).

Los monocitos circulantes, una vez que ingresan al tejido, sufren un proceso de maduración y transformación macrofágica en el cual aumentan de tamaño, adquieren un aparato de Golgi prominente y numerosos lisosomas. Los monocitos tienen un núcleo arriñonado o lobulado, que en general dobla en volumen al citoplasma. En cultivo se diferencian en macrófagos con un núcleo de bordes indentados e irregulares, una membrana plasmática que emite proyecciones digitiformes, y gran desarrollo del sistema de endomembranas (en virtud de su actividad fagocítica), con un aparato de Golgi desarrollado y numerosos lisosomas primarios y fagolisosomas. El aspecto vacuolado o "esponjoso" de su citoplasma es característico. Las características de la membrana plasmática y las endomembranas 
son más marcadas en los macrófagos activados. En la inflamación, los macrófagos aumentan también la cantidad de cuerpos lipídicos, inclusiones citoplasmáticas electrodensas carentes de membrana. En este trabajo de investigación se plantea el estudio morfológico ultraestructural del CCMII en macrófagos humanos derivados de monocitos sanguíneos en cultivo autólogo en un modelo de múltiples sinapsis inmunes que se basa en los resultados de un hallazgo del fenómeno: "Rosetas Macrófago-Linfocitarias” (RMLs) (Cabral \& Novak, 1992; Cabral \& Novak, 1999; Novak \& Cabral, 2008, 2009).

Las RMLs implican un tipo particular de asociación celular selectiva entre linfocitos autólogos humanos y macrófagos derivados de monocitos, a partir de cultivos de leucocitos totales extraídos de la sangre. Se define una RML como tres o más linfocitos unidos a un único macrófago central y corresponde a la interrelación de células TCD4+ con compromiso de su TCR con macrófagos a través de sus moléculas Clase II para la presentación antigénica. Su ocurrencia es tiempo de cultivo y densidad celular dependiente, de modo que leucocitos obtenidos recientemente de sangre periférica son incapaces de formar RMLs, y su desarrollo inicia después de 15 horas de cultivo, coincidiendo con la transformación macrofágica y la ingestión del material autólogo a partir de la muerte de neutrófilos también presentes en el cultivo celular total, los cuales tienen una vida media muy limitada in vitro (Cabral \& Novak, 1992; Cabral \& Novak, 1999; Novak \& Cabral, 2008, 2009). Inhibidores del procesamiento y la presentación antigénica y anticuerpos monoclonales anti-CMH clase II impiden el desarrollo de RMLs (Novak \& Cabral, 2008). En las RMLs se observó la redistribución de mitocondrias en linfocitos hacia la superficie de sinapsis inmune (Novak \& Orquera, 2011).

Es sabido que los macrófagos no siempre se activan hacia un perfil inflamatorio o M1, en presencia de células apoptóticas y bajo la influencia de ciertas citoquinas podrán diferenciarse hacia un perfil anti-inflamatorio o alternativo o $\mathrm{M} 2$, promoviendo además, la diferenciación de células $T$ reguladoras importantes en la tolerancia inmune (Mosser \& Edwards, 2008; Fainboim \& Geffner, 2011). Los macrófagos son las células encargadas del reconocimiento y fagocitosis de células propias que sufren apoptosis naturalmente en el organismo (Homburg \& Roos, 1996; Brown et al., 2002; Reddy et al., 2002). De esta manera se evita que el organismo reaccione, por ejemplo, frente a células apoptóticas naturales como los neutrófilos o eritrocitos senescentes o células de la mucosa en recambio, entre otras. El macrófago cumple así un rol fundamental en la generación de autotolerancia, ya que como CPA profesional está constantemente fagocitando elementos del medio ambiente del organismo y presentando porciones antigénicas con sus moléculas Clase II a las células $\mathrm{T}$, pero sin generar una respuesta inmune inflamatoria (Meagher et al., 1992).
Aquí se propone el estudio ultraestructural de la organización del CCMII en monocito-macrófagos humanos en cultivo durante el procesamiento y presentación de antígenos autólogos.

\section{Metodología}

Autorización ética: este trabajo fue aprobado por el Comité de Ética del Hospital Nacional de Clínicas de la Facultad de Ciencias Médicas, Universidad Nacional de Córdoba, Registro: 107/12. Se utilizaron muestras de sangre humana obtenidas con consentimiento informado, anticoagulada con heparina, de personas sanas ( $n=10,6$ varones $y$ 4 mujeres, rango de edad:21-58 años) donadas en anonimato por el Banco de Sangre, Instituto de Hematología y Hemoterapia (IHH) de la UNC. Las muestras de sangre fueron sometidas a las siguientes pruebas en el IHH, UNC: Hudleson (Wiener), VDRL (Wiener), Chagas HAI (Wiener), Chagas EIE (Biomerieux), HBs EIE (Biomerieux), HBC (Biomerieux), HCV EIE (Murex), HIV Ac EIE (Biomerieux), HIV Ag EIE (Biomerieux), HTLV EIE (Murex).

\section{Cultivos autólogos de leucocitos totales}

Las células fueron cultivadas en suspensión a $37^{\circ} \mathrm{C}$ en medio TC199 (con sales de Earle y L-glutamina) (SIGMA, St. Louis, MO) adicionado con suero del mismo dador. La densidad final de siembra fue ajustada a 300.000 células/ ml. Se utilizó el test clásico de exclusión Azul Tripan al 0,5\% para viabilidad celular. Se tomaron muestras a los siguientes tiempos de cultivo: 1h, 2hs. 3hs, 20 hs, 48 hs y 96 hs.

\section{Técnica de preparación de Rosetas Macrófago-Linfocitarias (RMLs)}

En todas las experiencias se utilizó la técnica de preparación de RMLs desarrollada en trabajos previos (Cabral \& Novak, 1992; Cabral \& Novak, 1999). La descripción original del fenómeno RML implica la participación de células T CD4 interactuando con un macrófago central, según nuestros trabajos previos publicados (Cabral \& Novak, 1999; Novak \& Cabral, 2008, 2009; Novak \& Orquera, 2011). Se define una RML cuando tres o más linfocitos establecen sinapsis inmune con un macrófago central quien con sus moléculas Clase Il presenta antígenos a células T CD4 (Cabral \& Novak, 1999; Novak \& Cabral, 2008, 2009; Novak \& Orquera, 2011).

\section{Citopreparaciones para Microscopía Electrónica de Transmisión (MET)}

Las citopreparaciones fueron fijadas en glutaraldehído al $1 \%$ en tampón cacodilato 0,1 M durante una hora y post fijados en $\mathrm{OsO}_{4}$ al $1 \%$ en el mismo tampón, durante una hora. Luego los materiales fueron deshidratados en acetonas de graduación creciente e incluidos en resina epoxi (Araldita) a $60^{\circ} \mathrm{C}$, durante 
24-48 hs. Posteriormente, se efectuaron cortes ultrafinos de 60 a $80 \mathrm{~nm}$ de espesor (color de interferencia plateado/dorado) que fueron recogidos en grillas de cobre de 250 barras por pulgada, contrastados con acetato de uranilo y citrato de Plomo y estudiados con microscopio electrónico de transmisión Zeiss LEO-906E en el Centro de Microscopia Electrónica, FCM, UNC.

\section{Registro de resultados}

A través de ultramicrofotografías tomadas por MET, se eligieron las imágenes más representativas de las muestras según el tiempo de cultivo. Representan al menos tres experimentos repetidos de donantes independientes.

\section{Resultados}

\section{Observaciones ultraestructurales}

El cultivo parte de la presencia de todos los tipos celulares leucocitarios, en ese tiempo los monocitos no se han diferenciado en macrófagos aún. No hubo ocurrencia de RMLs en las muestras obtenidas.

En las muestras de cultivo de una hora se observaron los diferentes tipos celulares. Solo algunos monocitos expresaron signos de inicio de diferenciación macrofágica y la mayoría tienen su tamaño y morfología habitual. Los neutrófilos son numerosos y presentan sus típicos gránulos, algunos se observan en asociación con otras células (Figura 1).

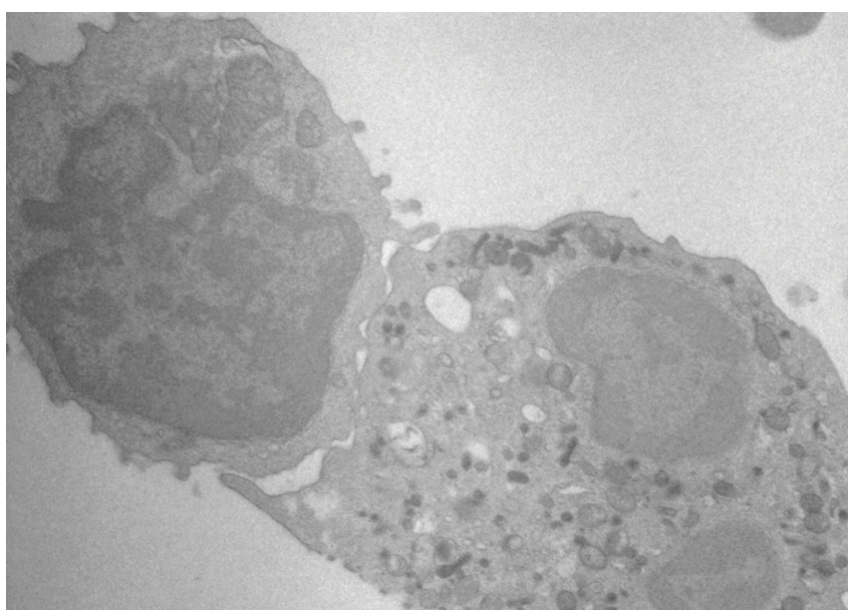

Figura 1. Interacción celular entre un monocito en transformación macrofágica y un neutrófilo.

1 h de cultivo autólogo de leucocitos totales de sangre humana de persona sana. Se observan los gránulos en el granulocito. MET, 7750x.

A las dos horas de cultivo autólogo de leucocitos totales, se aprecian signos de transformación macrofágica en los monocitos. Se observaron cuerpos multivesiculares en la organización espacial del CCMII y el aparato de Golgi bien desarrollado. Se observó un cuerpo multilaminar a nivel de membrana plasmática (Figura 2).

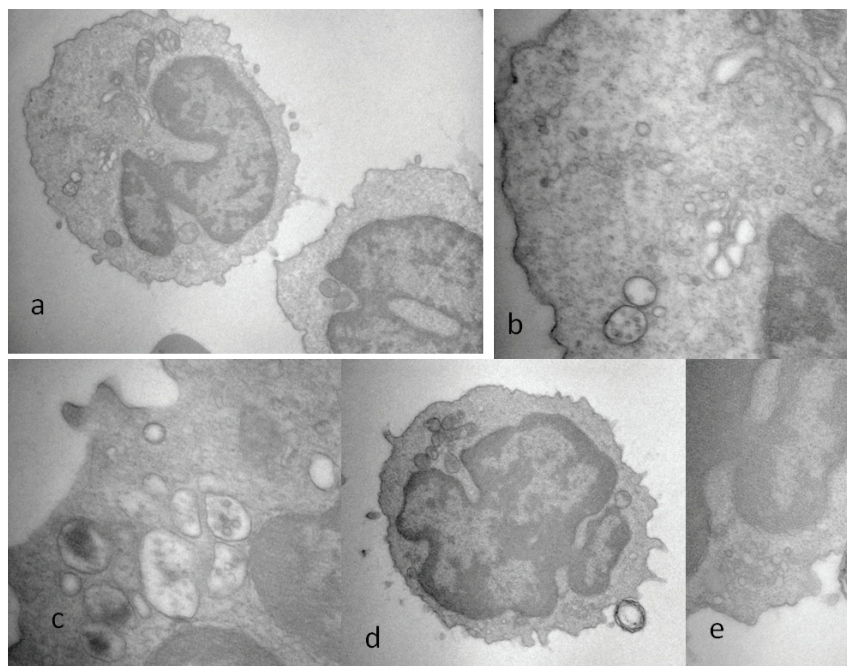

Figura 2. 2 horas de cultivo autólogo de leucocitos totales de sangre humana de persona sana. a. Monocitos. A la izquierda se observa una célula en transformación macrofágica. MET, 7750x. b. Porción del monocito en transformación macrofágica. Se observa gran desarrollo de aparato de Golgi y cuerpos multivesiculares abajo a la izquierda, MET, 21500x. c. Se observan cuerpos multivesiculares en la organización espacial del CCMII. MET, 36000x. d. Porción de monocito en transformación macrofágica. Se observa un cuerpo multilaminar compatible con CCMII a nivel de la membrana plasmática. MET, 10000x, e: 21000x.

Comenzó a apreciarse claramente, a las 3 horas de cultivo, la trasformación macrofágica en los monocitos. El citoplasma se observó cargado de lisosomas, y vesículas, algunas como cuerpos multivesiculares compatibles con CCMII (Figura 3).

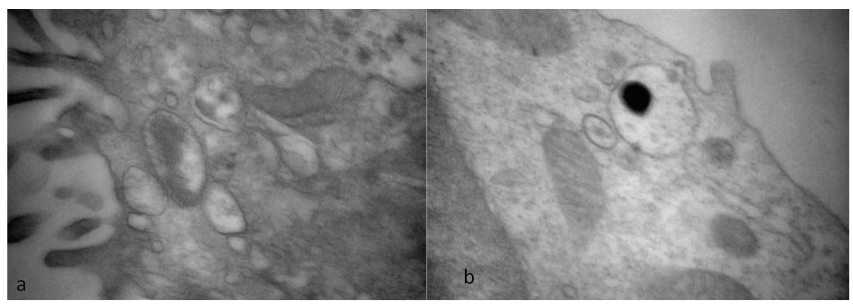

Figura 3. 3 horas de cultivo autólogo de leucocitos totales de sangre humana de persona sana. a. Porción de macrófago. Se observan vesículas de diferentes tamaños con contenido denso, y extensiones membranosas. MET, 36000x. b. Porción de monocito en transformación macrofágica, Se observan lisosomas y cuerpos multivesiculares electrodensos compatibles con CCMII. MET, 7750x.

A las 20 horas de cultivo en la mayoría de los neutrófilos se observaron evidentes signos de apoptosis, tales como la degradación nuclear y la desorganización y ruptura de los gránulos citoplasmáticos. Se los pudo apreciar en la vecindad de monocitos en avanzada 
transformación macrofágica. Se observó transformación macrofágica evidente con gran desarrollo de vesículas, lisosomas y el aparato de Golgi Además se pudieron apreciar cuerpos multivesiculares, algunos conectados con vesículas y elementos tubulares (Figura 4).

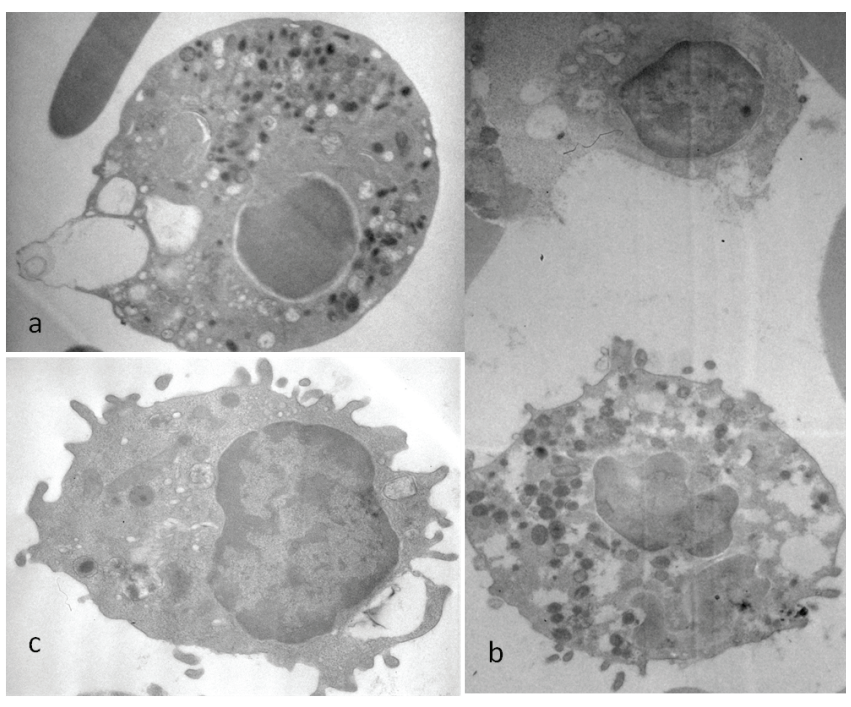

Figura 4. 20 horas de cultivo autólogo de leucocitos totales de sangre humana de persona sana. a. Neutrófilo con signos de apoptosis. MET, $10000 x$. b. Neutrófilo en aparente apoptosis a la derecha y monocito en transformación macrofágica a la izquierda. MET, 7550x. c. Se observa un monocito en transformación macrofágica avanzada, presenta prolongaciones irregulares y en su citoplasma abundantes lisosomas. El núcleo presenta abundante cromatina laxa. MET, 13000x.

A las 48 horas de cultivo en los macrófagos se observó la formación de cuerpos multilaminares y numerosas estructuras con aspecto tubular, además exhibieron grandes prolongaciones digitiformes. Las imágenes de fagocitosis de células apoptóticas fueron abundantes, observandose pseudópodos rodeando a las células (Figura 5). Este proceso indicaría que los macrófagos están ejerciendo, en el cultivo autólogo, la función de "limpieza" de células apoptóticas y desechos celulares del ambiente intersticial tal como la que ejercen normalmente en los tejidos del cuerpo, para lograr mantener la homeostasis.

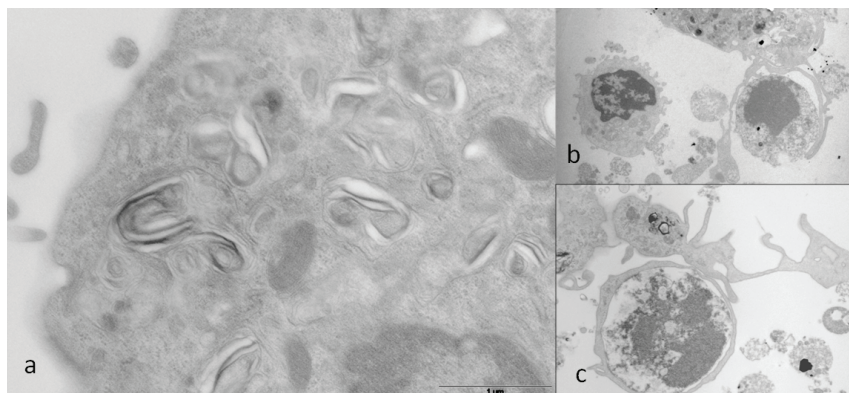

Figura 5. 48 horas de cultivo autólogo de leucocitos totales de sangre humana de persona sana. a. Se observan complejos con estructuras tubulares, multilaminares y vesículas compatibles con vesículas intermedias y tardías del CCMII. MET, 21000x. b. Se observan macrófagos fagocitando células apoptóticas. Se aprecia cómo los pseudópodos rodean a las células. MET, 3500x. c. 6600x.
A las 96 horas de cultivo se observaron numerosas asociaciones en RML en concordancia con trabajos previos descriptos (Cabral \& Novak, 1999; Novak \& Cabral, 2008, 2009; Novak \& Orquera, 2011). Los macrófagos se observaron con el citoplasma altamente vacuolado y sus prolongaciones membranosas típicas. Se apreció en la ultraestructura de los macrófagos maduros, el núcleo eucromático, el citoplasma cargado de vesículas y estructuras compatibles con CCMII multilaminares y multivesiculares, coincidiendo con el tiempo en que los macrófagos están presentando los antígenos que han procesado luego de la fagocitosis de los neutrófilos senescentes. Las estructuras multilaminares se encuentran en mayor proporción en este tiempo de cultivo. Se observaron también inclusiones lipídicas. A nivel de la membrana plasmática de los macrófagos se aprecian las proyecciones digitiformes y exosomas. (Figura 6). Estos resultados indicarían que los macrófagos estarían en una etapa final hacia la presentación antigénica, con sus moléculas Clase II cargadas con los péptidos para la ulterior presentación en la superficie celular.

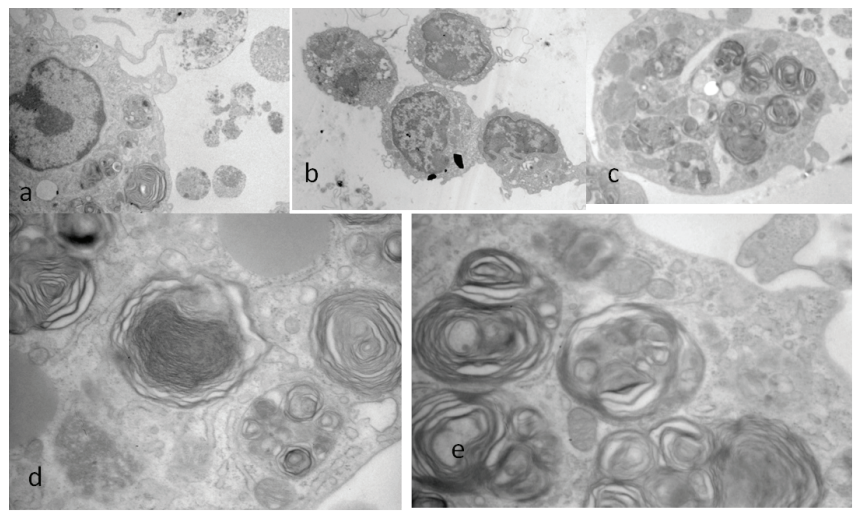

Figura 6. 96 horas de cultivo autólogo de leucocitos totales de sangre humana de persona sana. a. Porción de un macrófago con nucléolo evidente y cuerpos multivesiculares y multilaminares. MET, 3500x. b. Roseta macrófago-linfocitaria autóloga humana (RML). MET, 4600x. c. Macrófago con abundantes cuerpos multilaminares. d. Porción de macrófago con numerosos cuerpos multilaminares concéntricos y una estructura compatible con vesículas intermedias, que poseen cuerpos vesiculares y laminares en su interior abajo a la derecha. MET, 16700x. e. Porción de macrófago. Se observa una vesícula intermedia en el centro, numerosos cuerpos multilaminares, pequeñas mitocondrias y vesículas a la altura de la membrana plasmática. MET, 16700x.

\section{Discusión y conclusiones}

Aquí se planteó el estudio morfológico ultraestructural del CCMII en macrófagos humanos derivados de monocitos sanguíneos en cultivo autólogo en un modelo de múltiples sinapsis inmunes. En la literatura científica se han reportado estudios sobre la organización espacial del CCMII en células dendríticas y linfocitos B en modelos 
murinos como se mencionó anteriormente. En dichos modelos murinos se ha descripto su organización espacial en la maduración de las células dendríticas, con aspectos multivesiculares intermedios y multilaminares, tardíos respectivamente (van Nispen tot Pannerden et al., 2010). Estudios en células dendríticas de ratones indicarían que las vesículas internas de los cuerpos multivesiculares o endosomas tardíos multivesiculares serían la fuente principal de las moléculas Clase II hacia la membrana plasmática por un mecanismo de fusión retrógrada (Murk et al., 2004).

El camino exacto por el cual el complejo péptido-molécula Clase II es transportado hacia la superficie celular no está completamente entendido aún. Estudios en modelos con ratones han mostrado que durante la activación y en la interacción de células dendríticas con células T, el CCMII sufre grandes cambios estructurales y se transforma en compartimientos tubulares. Se cree que estos túbulos se forman en un camino dependiente de microtúbulos y contienen grandes cantidades de moléculas Clase II en sus membranas limitantes. Se sugirió que la fusión de la membrana interna del CCMII con la membrana limitante facilitaría la carga del péptido y el transporte del complejo péptido-CMH II hacia la membrana plasmática (Kleijmeer et al., 2001). La fusión podría promover la asociación del CMH II con la chaperona HLA-DM, que reside principalmente en la membrana limitante del CCMII. Esto podría facilitar la liberación del CLIP de la hendidura peptídica del CMH II, permitiendo así la carga del péptido. La fusión genera así mismo el suministro necesario de membrana para la tubulación del CCMII y el camino hacia la membrana plasmática (van Nispen tot Pannerden et al., 2010).

El paso final para el transporte del CMH II sería entonces la fusión de los túbulos con la membrana plasmática y/o la gemación y subsecuente fusión de las vesículas de transporte con la membrana plasmática. Se han descripto exosomas, vesículas membranosas entre 30 y $100 \mathrm{~nm}$ de diámetro, de CPAs desplegando moléculas Clase I y Clase II así como moléculas coestimuladoras (Johansson et al., 2008). Parte de las membranas luminares del CCMII son también secretadas como exosomas cuando este CCMII se fusiona con la membrana plasmática, descripto como un proceso constitutivo en las células dendríticas y las células B en modelos murinos (van Nispen tot Pannerden et al., 2010).

Cabe aclarar que la descripción original del fenómeno RML implica la participación de células T CD4 interactuando con un macrófago central, según nuestros trabajos previos publicados (Cabral \& Novak, 1992; Cabral \& Novak, 1999; Novak \& Cabral, 2008, 2009; Novak \& Orquera, 2011). Aquí en este estudio ultraestructural del CCMII en macrófagos humanos observamos cuerpos multivesiculares, multilaminares y tubulares a lo largo del tiempo de cultivo, en coincidencia con las estructuras intermedias y tardías descriptas en experimentos en ratones con otras CPAs (Kleijmeer et al., 2001; Murk et al., 2004; van Nispen tot Pannerden et al., 2010).

Postulamos que el perfil de los macrófagos que se generaron en el cultivo autólogo podría corresponderse al perfil alternativo o M2 involucrados en la generación de autotolerancia, dado que los antígenos presentados en el modelo de RML son autólogos derivados de la natural apoptosis de los neutrófilos que ocurre en el transcurso del tiempo de cultivo. Esta organización del CCMII en macrófagos en el modelo RML a lo largo del tiempo de cultivo sufre profundos cambios estructurales, esto coincide con la ocurrencia de transformación macrofágica y su rol como CPA, que se evidencia en la presentación antigénica en RMLs por ingestión del material autólogo a partir de la muerte de neutrófilos de vida breve en el cultivo celular total. Esto recuerda la fagocitosis de células propias que sufren apoptosis naturalmente en el organismo (Homburg \& Roos, 1996; Brown et al., 2002; Reddy et al., 2002). Es sabido además que macrófagos maduros reconocen y fagocitan neutrófilos humanos senescentes apoptóticos sin inducción de la liberación de mediadores de inflamación (Meagher et al., 1992).

Se estima de interés en estudios ulteriores el análisis de la organización del CCMII con el agregado de diversos antígenos exógenos, y su correlación con los perfiles fenotípicos de macrófagos, así como también el estudio de la expresión de moléculas co-estimuladoras y citoquinas en diferentes condiciones experimentales. Los macrófagos son importantes células inmunes que continuamente procesan y presentan antígenos por la vía endocítica con sus moléculas clase II del CMH a los linfocitos T CD4+. Su rol en la manutención de la autotolerancia es destacado. Se considera que este estudio ultraestructural de la organización espacial del CCMII en macrófagos humanos aporta nuevos datos de interés para la comunidad médica científica.

\section{Contribuciones y reconocimiento}

N.S. Infante realizó la mayoría de los experimentos, analizó los datos y escribió parte del manuscrito. I.T.C. Novak diseñó y dirigió este trabajo de investigación, interpretó los datos y finalizó el manuscrito. Los autores declaran ausencia de conflictos de interés.

\section{Agradecimientos}

Al Banco de Sangre del Instituto de Hematología y Hemoterapia de la Universidad Nacional de Córdoba, Argentina, por la donación de las muestras sanguíneas. 


\section{Referencias}

Abbas AK, Lichtmann AH \& Pillai S. (2012). Inmunología Celular y Molecular, 8a Edición. Elsevier, Barcelona.

Bromley SK, laboni A, Davis SJ, Whitty A, Green JM, Shaw AS, Weiss A \& Dustin ML. (2001). The immunological synapse and CD28-CD80 interactions. Nat Immunol 2, 1159-1166.

Brown S, Heinisch I, Ross E, Shaw K, Buckley CD \& Savill J. (2002). Apoptosis disables CD31-mediated cell detachment from phagocytes promoting binding and engulfment. Nature 418, 200-203.

Cabral HR \& Novak I. (1992). Spontaneous formation of rosettes by autologous human monocyte-macrophages and lymphocytes in cell cultures. Rev Fac Cien Med Univ Nac Cordoba 50, 25-26.

Cabral HR \& Novak IT. (1999). Autologous rosette formation by human blood monocyte-derived macrophages and lymphocytes. Am J Hematol 60, 285-288.

Dustin ML, Allen PM \& Shaw AS. (2001). En0vironmental control of immunological synapse formation and duration. Trends Immunol 22, 192-194.

Fainboim L \& Geffner J. (2011). Introducción a la Inmunología Humana,6a Edición. Editorial Médica Panamericana, Buenos Aires.

Grakoui A, Bromley SK, Sumen C, Davis MM, Shaw AS, Allen PM \& Dustin ML. (1999). The immunological synapse: a molecular machine controlling $T$ cell activation. Science $\mathbf{2 8 5}$, 221-227.

Homburg CH \& Roos D. (1996). Apoptosis of neutrophils. Curr Opin Hematol 3, 94-99.

Johansson SM, Admyre C, Scheynius A \& Gabrielsson S. (2008). Different types of in vitro generated human monocyte-derived dendritic cells release exosomes with distinct phenotypes. Immunology 123, 491-499.

Kleijmeer M, Ramm G, Schuurhuis D, Griffith J, Rescigno M, Ricciardi-Castagnoli P, Rudensky AY, Ossendorp F, Melief CJ, Stoorvogel W \& Geuze HJ. (2001). Reorganization of multivesicular bodies regulates $\mathrm{MHC}$ class II antigen presentation by dendritic cells. $J$ Cell Biol 155, 53-63.

Kupfer A \& Dennert G. (1984). Reorientation of the microtubule-organizing center and the Golgi apparatus in cloned cytotoxic lymphocytes triggered by binding to lysable target cells. J Immunol 133, 2762-2766.
Kupfer A, Dennert G \& Singer SJ. (1983). Polarization of the Golgi apparatus and the microtubule-organizing center within cloned natural killer cells bound to their targets. Proc Natl Acad Sci U S A 80, 7224-7228.

Lee $\mathrm{KH}$, Holdorf AD, Dustin ML, Chan AC, Allen PM \& Shaw AS. (2002). T cell receptor signaling precedes immunological synapse formation. Science 295, 1539-1542.

Lin J, Miller MJ \& Shaw AS. (2005). The c-SMAC: sorting it all out (or in). The Journal of Cell Biology 170, 177-182.

Meagher LC, Savill JS, Baker A, Fuller RW \& Haslett C. (1992). Phagocytosis of apoptotic neutrophils does not induce macrophage release of thromboxane B2. Journal of Leukocyte Biology 52, 269-273.

Mitxitorena I, Saavedra E \& Barcia C. (2015). Kupfer-type immunological synapses in vivo: Raison D'etre of SMAC. Immunol Cell Biol 93, 51-56.

Mosser DM \& Edwards JP. (2008). Exploring the full spectrum of macrophage activation. Nat Rev Immunol 8, 958-969.

Murk JL, Lebbink MN, Humbel BM, Geerts WJ, Griffith JM, Langenberg DM, Verreck FA, Verkleij AJ, Koster AJ, Geuze HJ \& Kleijmeer MJ. (2004). 3-D Structure of multilaminar lysosomes in antigen presenting cells reveals trapping of $\mathrm{MHC}$ II on the internal membranes. Traffic 5, 936-945.

Murphy KP. (2012). Janeway's Immunobiology,8a Edición. Garlands Science, New York.

Neefjes J, Jongsma MLM, Paul P \& Bakke O. (2011). Towards a systems understanding of $\mathrm{MHC}$ class I and $\mathrm{MHC}$ class II antigen presentation. Nat Rev Immunol 11, 823-836.

Novak IT \& Cabral HR. (2008). Rosettes formation by macrophages with adhered $\mathrm{T}$ lymphocytes is precluded by inhibitors of antigen processing-presentation. Biocell 32, 169-174.

Novak IT \& Cabral HR. (2009). Immunological Synapses Formation: Rosettes between Human Autologous Cultured Monocyte-Macrophages and Lymphocytes Proceedings of ECI. In Medimond International Proceedings, L913C0012, pp. 117-121. Medimond International Proceedings.

Novak IT \& Orquera AD. (2011). Mitochondrial Translocation in Lymphocytes of Human Autologous Macrophage-Lymphocyte Rosettes. Mol Biol Cell 22 (suppl), abstract. 
Infante et al.

Reddy SM, Hsiao KH, Abernethy VE, Fan H, Longacre A, Lieberthal W, Rauch J, Koh JS \& Levine JS. (2002). Phagocytosis of apoptotic cells by macrophages induces novel signaling events leading to cytokine-independent survival and inhibition of proliferation: activation of Akt and inhibition of extracellular signal-regulated kinases 1 and 2. J Immunol 169, 702-713.
Van Nispen tot Pannerden HE, Geerts WJ, Kleijmeer MJ \& Heijnen HF. (2010). Spatial organization of the transforming MHC class II compartment. Biol Cell 102, 581-591. 